\title{
Epicardial adipose tissue volume and coronary calcification among people living with diabetes: a cross-sectional study
}

\author{
Emmanuel Cosson ${ }^{1,2^{*}}$, Minh Tuan Nguyen ${ }^{3}$, Imen Rezgani ${ }^{1}$, Sopio Tatulashvili ${ }^{1}$, Meriem Sal ${ }^{1}$, \\ Narimane Berkane ${ }^{1}$, Lucie Allard ${ }^{1}$, Pierre-Yves Brillet ${ }^{4}$ and Hélène Bihan ${ }^{1,5}$
}

\begin{abstract}
Background: Epicardial adipose tissue (EAT) has anatomic and functional proximity to the heart and is considered a novel diagnostic marker and therapeutic target in cardiometabolic diseases. The aim of this study was to evaluate whether EAT volume was associated with coronary artery calcification (CAC) in people living with diabetes, independently of confounding factors.
\end{abstract}

Methods: We included all consecutive patients with diabetes whose EAT volume and CAC score were measured using computed tomography between January 1, 2019 and September 30, 2020 in the Department of DiabetologyEndocrinology-Nutrition at Avicenne Hospital, France. Determinants of EAT volume and a CAC score $\geq 100$ Agatston units (AU) were evaluated.

Results: The study population comprised 409 patients (218 men). Mean ( \pm standard deviation) age was $57 \pm 12$ years, and 318, 56 and 35 had type 2 (T2D), type 1 (T1D), or another type of diabetes, respectively. Mean body mass index (BMI) was $29 \pm 6 \mathrm{~kg} / \mathrm{m}^{2}$, mean AET volume $93 \pm 38 \mathrm{~cm}^{3}$. EAT volume was positively correlated with age, $\mathrm{BMI}$, pack-year smoking history and triglyceridaemia, but negatively correlated with HDL-cholesterol level. Furthermore, it was lower in people with retinopathy, but higher in men, in Caucasian people, in patients on antihypertensive and lipid-lowering medication, in people with nephropathy, and finally in individuals with a CAC $\geq 100$ AU (CAC $<100$ vs $C A C \geq 100: 89 \pm 35$ vs $109 \pm 41 \mathrm{~cm}^{3}$, respectively, $\left.p<0.05\right)$. In addition to EAT volume, other determinants of $C A C \geq 100 \mathrm{AU}(\mathrm{n}=89,22 \%)$ were age, T2D, ethnicity, antihypertensive and lipid-lowering medication, cumulative tobacco consumption, retinopathy, macular edema and macrovascular disease. Multivariable analysis considering all these determinants as well as gender and BMI showed that EAT volume was independently associated with $C A C \geq 100 \mathrm{AU}$ (per $10 \mathrm{~cm}^{3}$ increase: OR 1.11 [1.02-1.20]).

Conclusions: EAT volume was independently associated with CAC. As it may play a role in coronary atherosclerosis in patients with diabetes, reducing EAT volume through physical exercise, improved diet and pharmaceutical interventions may improve future cardiovascular risk outcomes in this population.

Keywords: Computed tomography, Coronary artery calcification, Diabetes, Epicardial adipose tissue, Epicardial fat tissue, Metabolic syndrome, Visceral fat

\footnotetext{
*Correspondence: emmanuel.cosson@aphp.fr

${ }^{1}$ Department of Endocrinology-Diabetology-Nutrition, AP-HP, Avicenne Hospital, Université Paris 13, Sorbonne Paris Cité, CRNH-IdF, CINFO, Bobigny, France

Full list of author information is available at the end of the article
}

\section{Background}

Type 1 (T1D) and type 2 diabetes (T2D) are associated with an increased risk of cardiovascular disease, irrespective of improved multifactorial care [1,2]. Epicardial adipose tissue (EAT) has recently been proposed as one

c) The Author(s) 2021. This article is licensed under a Creative Commons Attribution 4.0 International License, which permits use, sharing, adaptation, distribution and reproduction in any medium or format, as long as you give appropriate credit to the original author(s) and the source, provide a link to the Creative Commons licence, and indicate if changes were made. The images or other third party material in this article are included in the article's Creative Commons licence, unless indicated otherwise in a credit line to the material. If material is not included in the article's Creative Commons licence and your intended use is not permitted by statutory regulation or exceeds the permitted use, you will need to obtain permission directly from the copyright holder. To view a copy of this licence, visit http://creativeco mmons.org/licenses/by/4.0/. The Creative Commons Public Domain Dedication waiver (http://creativecommons.org/publicdomain/ zero/1.0/) applies to the data made available in this article, unless otherwise stated in a credit line to the data. 
determinant contributing to the pathophysiology of cardiovascular complications [3-6]. A recent meta-analysis showed that individuals with diabetes had higher EAT volumes than healthy controls, irrespective of T1D or T2D status and the method used to quantify EAT volume [3].

EAT is located between the myocardium and the visceral pericardium and is considered the heart's visceral adipose tissue [3-6]. It secretes inflammatory factors and lipid metabolites, and has been suggested as a possible determinant of accelerated atherosclerosis [3-6]. However, at the clinical level, evidence that EAT is a marker of subclinical atherosclerosis in diabetic populations is still limited [5].

Coronary artery calcium (CAC) is considered a good marker of coronary risk [7]. The CAC score assesses the volume of coronary calcifications located in atherosclerotic plaques and provides a summary measure of atherosclerotic disease, reflecting the cumulative lifetime effect of risk factors and genetic and environmental factors [7]. The CAC score increases with cardiovascular risk in both the general population and in people with diabetes [810] and a threshold of 100 Agatston units (AU) is commonly used to identify the individuals at high risk [7-10]. To date, only four studies which have evaluated the association either between EAT volume [11-13] or EAT thickness [14] and CAC score in patients with diabetes have had mixed results: one study showed a positive association between EAT and CAC score in 333 patients without cardiovascular disease or renal impairment [11]; another only showed an association in the 38 individuals out of 95 studied who had early-onset T2D [13], while the remaining two studies reported no association whatsoever $[12,14]$.

In this context, the present study aimed to evaluate, in a large cohort of people living with diabetes, whether EAT volume was associated with CAC score, independently of confounding factors.

\section{Methods}

\section{Study population}

The present retrospective study involved each consecutive patient with diabetes admitted to the Department of Diabetology-Endocrinology-Nutrition, in Avicenne Hospital, Bobigny, France, between January 1, 2019 and September 30, 2020. All had a computed tomography (CT) scan during hospitalization to evaluate their CAC score (AU) and assess their cardiovascular risk $[8,10]$.

\section{CT imaging}

CAC scores and EAT volume were calculated using ECG-gated cardiac CT without contrast injection. All CT scans were performed with GE (Healthcare Digital,
France) or Siemens (Healthineers, France) scanners. CAC scores were calculated according to guidelines [15] using the dedicated tool available on Picture Archiving and Communication Systems (PACS) platforms (either from Carestream Health, Rochester, NY or Philips Healthcare, Best, the Netherlands). EAT volume was quantified with the software package AW VolumeShare 7 (GE Healthcare Digital). It was measured using a semi-automatic segmentation technique on every axial slice from the thoracic inlet to the beginning of the abdomen. The software automatically measured EAT volume (in $\mathrm{cm}^{3}$ ) by summing appropriate pixels using a CT Hounsfield unit, range -150 to $-50 \mathrm{HU}$.

\section{Data collection}

Data were extracted from patients' medical records and collected in a secure health database. For the present study, we focused on:

- General data: current tobacco consumption and pack-year smoking history, diagnosed premature (before 55 years for men; before 65 years for women) coronary artery disease in first degree relatives; ethnicity (recorded as Caucasian, Arabic (Middle East, North Africa), Afro-Caribbean (African, African American, Caribbean), Asian (Asian continent), or other).

- Medical history: routine treatments before admission, history of stroke, heart failure, or coronary artery disease. Hypertension and dyslipidaemia were self-reported and/or inferred from blood pressureand lipid-lowering agents, respectively. Additionally, we collected data to measure possible overweightness (body mass index $(\mathrm{BMI}) \geq 25 \mathrm{~kg} / \mathrm{m}^{2}$ ) and obesity $\left(\mathrm{BMI} \geq 30 \mathrm{~kg} / \mathrm{m}^{2}\right)$. BMI was calculated using the formula: weight $(\mathrm{kg}) /$ height $^{2}\left(\mathrm{~m}^{2}\right)$. Weight and height were measured within $24 \mathrm{~h}$ of hospital admission.

- Biomarkers: HbA1c (high performance liquid chromatography variant); total and HDL cholesterol (colorimetric assay on homogenous phase and cholesterol dosage by cholesterol oxidase), triglycerides (colorimetric assay), and LDL-cholesterol (calculated using the Friedewald formula). All these measurements were performed on plasma from fasting individuals using a Cobas 6000 analyzer (Roche diagnostics). Serum creatinine was measured (colorimetry, Kone Optima, Thermolab System, Paris La Défense, France) and creatinine clearance estimated (using the Chronic Kidney Disease-Epidemiology Collaboration equation). The urinary albumin/creatinine ratio (UACR) was measured (laser immunonephelometry, BN100, Dade-Behring, Paris, France). 
- Diabetes-related complications: retinopathy (defined as any medical argument for a retinopathy); nephropathy [defined as renal failure (estimated creatinine clearance $<60 \mathrm{~mL} / \mathrm{min}$ ) and/or albuminuria (UACR $>3 \mathrm{mg} / \mathrm{mmol}$ )]; neuropathy (defined as any sign or symptoms of polyneuropathy); peripheral arterial occlusive disease (stenosis measured $50 \%$ by ultrasound examination); macroangiopathy (defined as peripheral arterial occlusive disease or history of stroke, heart failure or coronary artery disease).

\section{Statistical analyses}

Continuous variables were expressed as means \pm standard deviation and compared using one-way ANOVA or the Mann-Whitney's U test as appropriate. No data replacement procedure was used for missing data. Pearson's and/or Spearman's correlations were performed to identify the parameters associated with EAT. The $\chi^{2}$ test was used to measure significant differences between the proportion of patients with a CAC score $<100$ and those with a score $\geq 100 \mathrm{AU}$. Logistic regression was performed for the multivariable analysis, which included only those parameters associated with a CAC score $\geq 100 \mathrm{AU}$, as well as BMI and gender. Odds ratios with 95\% confidence intervals $(95 \mathrm{CI})$ for the risk of a CAC score $\geq 100$ AU were calculated. Statistical analyses were performed using SPSS software (SPSS, Chicago, IL). The level of significance for all tests was $\mathrm{p}<0.05$.

\section{Results}

\section{Patient characteristics}

Of the 410 patients who met study inclusion criteria, 1 was not included as the EAT volume could not be measured. The characteristics of the 409 included patients are shown in Table 1.

\section{Parameters associated with EAT}

EAT volume was positively associated with age, BMI, triglyceride levels, cumulative tobacco consumption and CAC score. It was negatively correlated with creatinine clearance and HDL-cholesterol level (Table 2). EAT volume was higher in males, overweight and obese persons, those categorized as Caucasian, patients with T2D, those with hypertension, individuals with dyslipidaemia and people with a CAC score $\geq 100$ AU (Fig. 1, Additional file 1: Table S1). It was also higher in participants with nephropathy and albuminuria, but lower in patients with retinopathy (Fig. 2, Additional file 1: Table S2).

Additional file 1: Table S3 also shows that the use of the following treatments was associated with a higher EAT volume: metformin, sulfonylurea, glucagon-like peptide 1 receptor agonists, beta-blockers, statins and aspirin.
Table 1 Patient characteristics

\begin{tabular}{|c|c|c|}
\hline & Available data & Total \\
\hline \multicolumn{3}{|l|}{ Clinical characteristics } \\
\hline Age (years) & $n=409$ & $57.1 \pm 12.4$ \\
\hline Gender (Male/Female) & $n=409$ & 218/191 \\
\hline Body mass index $\left(\mathrm{kg} / \mathrm{m}^{2}\right)$ & $n=403$ & $29.1 \pm 5.9$ \\
\hline Overweight or obese & $n=403$ & $325(79.5)$ \\
\hline Obese & $n=403$ & $158(38.6)$ \\
\hline Ethnicity & $n=408$ & \\
\hline Caucasian & & $88(21.5)$ \\
\hline Sub-Saharan Africa-Antilles & & $103(25.2)$ \\
\hline Middle East, North Africa & & $146(35.7)$ \\
\hline Asia & & $57(14.0)$ \\
\hline Other & & $14(3.4)$ \\
\hline \multicolumn{3}{|l|}{ Diabetes } \\
\hline Type & $n=409$ & \\
\hline Type 1 & & $56(13.7)$ \\
\hline Type 2 & & $318(77.8)$ \\
\hline Other & & $35(8.6)$ \\
\hline \multicolumn{3}{|l|}{ Treatment } \\
\hline Oral antidiabetic agents & $n=408$ & $295(72.1)$ \\
\hline Glucagon-like peptid 1 agonists & $n=408$ & $75(18.3)$ \\
\hline Insulin & $n=408$ & $252(61.6)$ \\
\hline Time since diagnosis (years) & $n=409$ & $14.0 \pm 10.2$ \\
\hline $\mathrm{HbA1c}, \%$ & $n=403$ & $9.0 \pm 2.3$ \\
\hline Retinopathy & $n=392$ & $160(39.1)$ \\
\hline Macular edema & $n=382$ & $44(10.8)$ \\
\hline Nephropathy & $n=390$ & $148(36.2)$ \\
\hline Albuminuria & $\mathrm{n}=389$ & $135(33.0)$ \\
\hline Renal failure & $\mathrm{n}=409$ & $39(9.5)$ \\
\hline Neuropathy & $\mathrm{n}=401$ & $163(39.9)$ \\
\hline Peripheral arterial occlusive disease & $n=409$ & $37(9.0)$ \\
\hline History of stroke & $n=409$ & $13(3.2)$ \\
\hline History of heart failure & $n=356$ & $5(1.2)$ \\
\hline Coronary artery disease (CAD) & $n=409$ & $4(1.0)$ \\
\hline \multicolumn{3}{|l|}{ Additional cardiovascular risk factors } \\
\hline Family history of premature CAD & $n=149$ & $33(8.1)$ \\
\hline Hypertension & $n=408$ & $224(54.8)$ \\
\hline Systolic blood pressure (mmHg) & $n=408$ & $135 \pm 18$ \\
\hline Diastolic blood pressure $(\mathrm{mmHg})$ & $n=408$ & $77 \pm 13$ \\
\hline Dyslipidemia & $n=408$ & $238(58.2)$ \\
\hline Total cholesterol (mmol/L) & $n=409$ & $4.4 \pm 1.2$ \\
\hline HDL cholesterol (mmol/L) & $n=409$ & $1.2 \pm 0.4$ \\
\hline Triglycerides (mmol/L) & $n=409$ & $1.7 \pm 1.2$ \\
\hline LDL cholesterol (mmol/L) & $n=406$ & $2.4 \pm 0.9$ \\
\hline Non HDL cholesterol (mmol/L) & $n=409$ & $3.2 \pm 1.1$ \\
\hline Current smoking & $n=409$ & $71(17.4)$ \\
\hline Smoking history (pack-year) & $n=386$ & $8.2 \pm 16.6$ \\
\hline \multicolumn{3}{|l|}{ Computed tomography results } \\
\hline Epicardial adipose tissue volume $\left(\mathrm{cm}^{3}\right)$ & $n=409$ & $92 \pm 37$ \\
\hline CAC score (Agatston unit) & $n=409$ & $116 \pm 332$ \\
\hline
\end{tabular}

Data are $\mathrm{n}(\%)$ or mean \pm standard deviation

$C A C$ coronary artery calcium score, $C A D$ coronary artery disease 
Table 2 Correlation of epicardial adipose tissue volume with quantitative data

\begin{tabular}{lrc}
\hline & \multicolumn{1}{l}{ R } & p-value \\
\hline Age, years & 0.324 & $<0.0001$ \\
Body mass index, $\mathrm{kg} / \mathrm{m}^{2}$ & 0.288 & $<0.0001$ \\
HbA1c, \% & -0.093 & 0.142 \\
Urinary albumin/creatinin ratio, $\mathrm{mg} / \mathrm{mmol}$ & 0.059 & 0.260 \\
Creatinine clearance, $\mathrm{mL} / \mathrm{min}$ & -0.237 & $<0.0001$ \\
Systolic blood pressure, $\mathrm{mmHg}$ & -0.022 & 0.656 \\
Diastolic blood pressure, $\mathrm{mmHg}$ & -0.035 & 0.483 \\
Total cholesterol, mmol/L & -0.057 & 0.250 \\
HDL cholesterol, mmol/L & -0.190 & $<0.0001$ \\
Triglycerides, mmol/L & 0.150 & 0.002 \\
LDL cholesterol, mmol/L & -0.070 & 0.158 \\
Non HDL cholesterol, mmol/L & 0.005 & 0.925 \\
Smoking history (pack-year) & 0.233 & $<0.0001$ \\
Coronary artery calcium score, Agatston unit & 0.287 & $<0.0001$ \\
\hline
\end{tabular}

\section{Parameters associated with CAC}

Individuals with a CAC score $\geq 100$ AU (versus $<100$ $\mathrm{AU}$ ) were older, more likely to be Caucasian (versus Afro-Caribbean, Arabic and Asian), more likely to have T2D (versus T1D), and more likely to have retinopathy, macular edema, nephropathy, macrovascular disease, hypertension and dyslipidaemia. Furthermore, they had had diabetes for a longer time and had higher pack-year smoking history (Table 3 ). In the multivariable analysis, after adjustment for all these parameters and both gender and BMI, EAT was independently associated with a CAC score $\geq 100$ AU (Table 4).

\section{Discussion}

Our cohort study results show that EAT volume was independently associated with CAC in people with diabetes. This reflects results from another study with a mix of individuals with and without diabetes [16]. Similarly, Yerramasu et al. found that EAT volume was an independent marker of both the presence and severity of CAC burden in 333 asymptomatic patients with T2D [11]. However, the latter finding goes against results from three others studies where no such association was found [12-14]. There are several possible reasons for this. First, these three studies had less statistical power than Yerramasu's and ours, as they only included between 95 and 200 patients [12-14]. Second, one of the three (Christensen et al.) measured EAT thickness not volume [14]. Third, inclusion criteria differed between the three studies: only patients with T2D and elevated urinary albumin excretion rate were recruited in Christensen et al's study [14], while only young Native Americans with T2D were included in Reinhardt et al.'s study [13]. Our results in diabetic persons are clinically relevant as we were able to show that the association remained significant even after adjustment for numerous confounding factors.

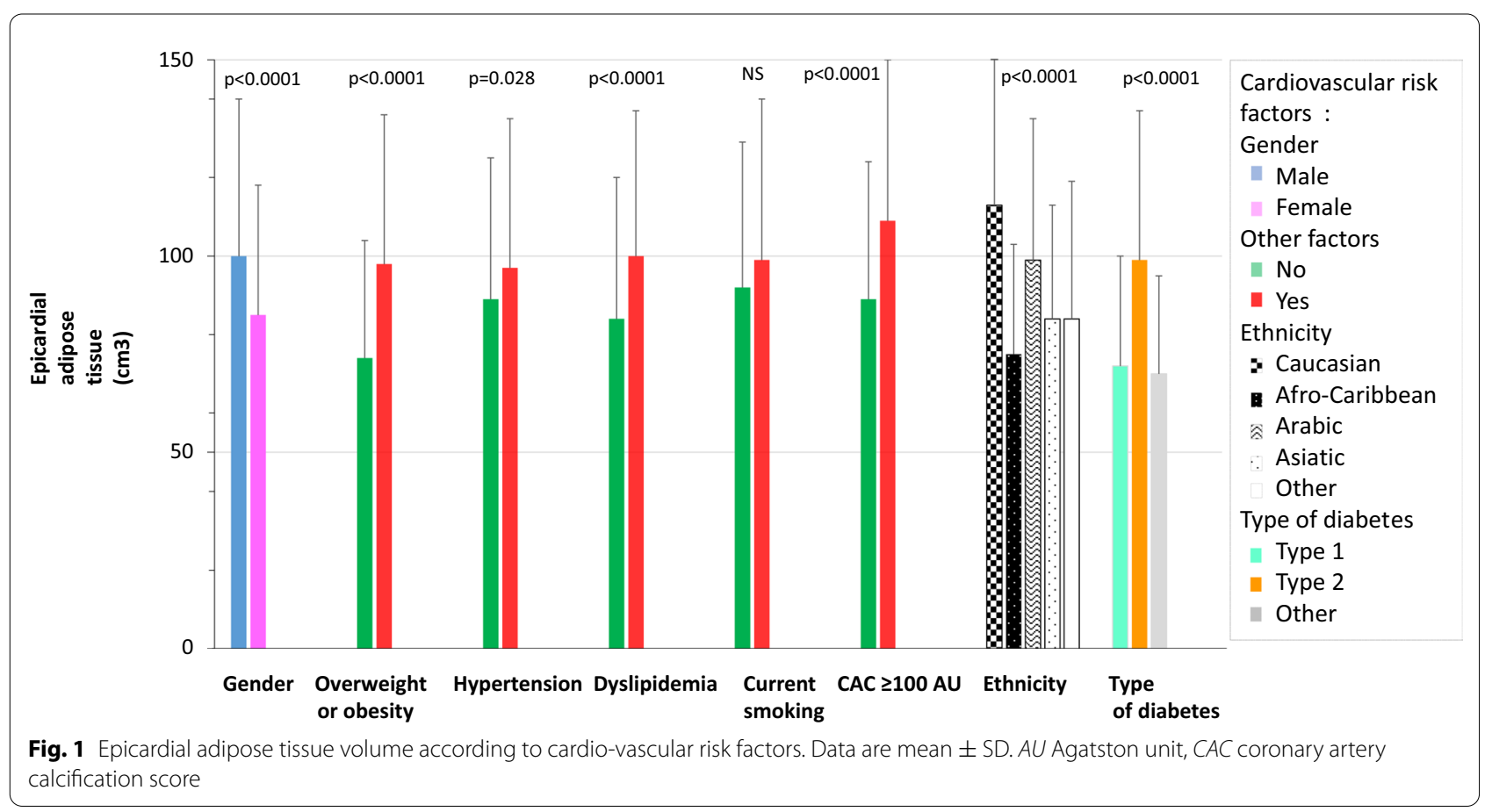




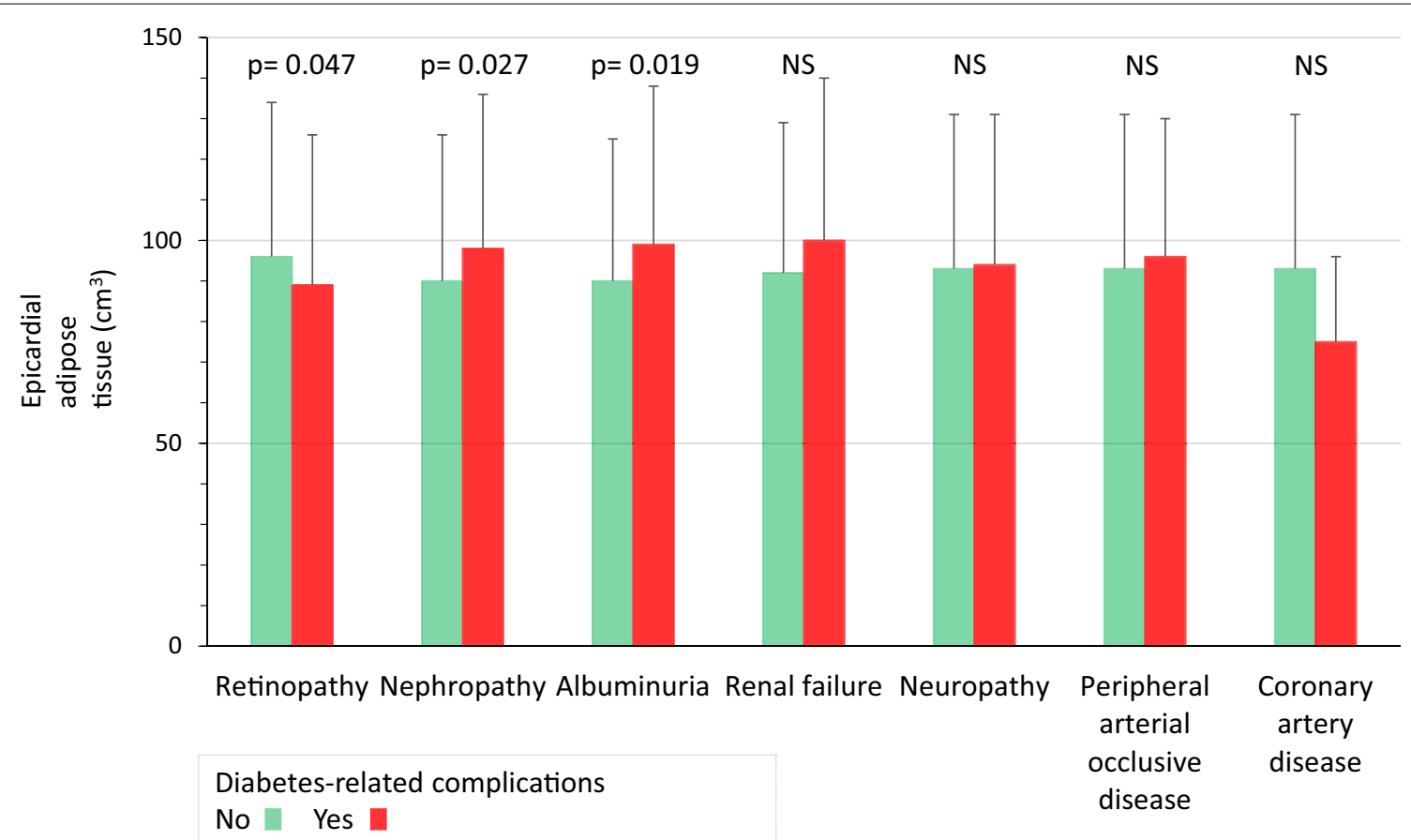

Fig. 2 Epicardial adipose tissue volume according to diabetes-related complications. Data are mean \pm SD

\section{Parameters associated with EAT volume, to be considered as confounders}

First, EAT volume was positively correlated with male gender and older age. Elsewhere, EAT volume has been associated with all the components of metabolic syndrome in people with T2D $[16,17]$ and those with T1D $[18,19]$. Similarly, we found an association between EAT volume and higher BMI, increased triglycerides levels, lower HDL-cholesterol levels and antihypertensive treatment. This result is in line with previous studies which showed a higher EAT volume in individuals with T2D than those with T1D $[12,19]$. Additionally, cumulative tobacco consumption, which is associated with insulin resistance and metabolic syndrome [20], was positively correlated with EAT volume in our study. Finally, we also found that EAT volume was higher in individuals of Caucasian ethnicity. Similarly, the difference in EAT thickness between persons with and without metabolic syndrome was more evident in Caucasians $[17,21]$. Other studies have also found that EAT levels differ according to racial/ethnic group in the general population [22-25].

\section{EAT and subclinical atherosclerosis, including CAC}

The association between EAT and CAC in our study suggests that EAT might play a role in subclinical atherosclerosis in diabetes. There are arguments to support this hypothesis. First, increased EAT volume/ thickness has been associated with markers of subclinical atherosclerosis other than CAC score, such as coronary artery disease and cardiac dysfunction [5]. Second, prospective studies have shown that high EAT volume/thickness is associated with more cardiovascular events in the general population [26], in patients with T2D without participant-selection study criteria [27] and T2D patients with microalbuminuria [14]. Third, EAT identifies individuals at increased risk of CAC progression [11]. Fourth, whereas EAT is physiologically cardioprotective-as it provides mechanical protection and energy to the myocardium and has antiinflammatory properties-, abnormally increases in EAT volume are proinflammatory [3-6]. Furthermore, EAT secretes vasoactive factors that regulate coronary endothelial function and facilitate free fatty acid influx [3-6]. Therefore, the positive association between EAT and CAC may reflect early pathophysiological effects of EAT on local atherosclerosis. EAT volume could therefore be considered as a surrogate of coronary atherosclerosis. Similarly, EAT volume has been associated with plaque vulnerability, which may contribute to acute coronary syndrome [28]. Finally, EAT might in addition directly promote calcification processes in atheroma [29]. 
Table 3 Patient characteristics according to coronary artery calcium scores < or $\geq 100$ Agatston units

\begin{tabular}{|c|c|c|c|c|}
\hline & $\begin{array}{l}\mathrm{CAC}<100 \mathrm{AU} \\
\mathrm{n}=320\end{array}$ & $\begin{array}{l}C A C \geq 100 A U \\
n=89\end{array}$ & OR $[95 \% \mathrm{Cl}]$ & $\mathrm{p}$ \\
\hline \multicolumn{5}{|l|}{ Clinical characteristics } \\
\hline Age (years) & $54.7 \pm 12.2$ & $65.7 \pm 8.7$ & & $<0.0001$ \\
\hline Gender (Male/Female) & $164 / 156$ & $54 / 35$ & $0.7[0.4-1.1]$ & 0.120 \\
\hline Body mass index $\left(\mathrm{kg} / \mathrm{m}^{2}\right)$ & $29.3 \pm 6.0$ & $28.2 \pm 5.5$ & & 0.119 \\
\hline \multicolumn{5}{|l|}{ Ethnicity } \\
\hline Caucasian & $57(17.9)$ & $31(34.8)$ & REF & \\
\hline Afro-Caribbean & $88(27.6)$ & 15(16.9) & $0.3[0.2-0.6]$ & 0.001 \\
\hline Arabic & 116(36.4) & $30(33.7)$ & $0.5[0.3-0.9]$ & 0.014 \\
\hline Asia & $47(14.7)$ & $10(11.2)$ & $0.4[0.2-0.9]$ & 0.023 \\
\hline Other & $11(3.4)$ & $3(3.4)$ & $0.5[0.1-1.9]$ & 0.316 \\
\hline \multicolumn{5}{|l|}{ Diabetes } \\
\hline \multicolumn{5}{|l|}{ Type } \\
\hline Type 1 & $52(16.2)$ & $4(4.5)$ & REF & \\
\hline Type 2 & $239(74.7)$ & 79(88.8) & $4.3[1.5-12.3]$ & 0.006 \\
\hline Other & $29(9.1)$ & $6(6.7)$ & $2.7[0.7-10.3]$ & 0.149 \\
\hline Time since diagnosis (years) & $12.9 \pm 9.8$ & $17.7 \pm 10.8$ & & $<0.0001$ \\
\hline $\operatorname{HbA1c}(\%)$ & $9.0 \pm 2.3$ & $8.7 \pm 2.1$ & & 0.280 \\
\hline \multicolumn{5}{|l|}{ Diabetes-related complication } \\
\hline Retinopathy & 116(37.8) & $44(51.8)$ & $1.8[1.1-2.9]$ & 0.025 \\
\hline Macular edema & $28(9.3)$ & 16(19.5) & $2.4[1.2-4.6]$ & 0.018 \\
\hline Nephropathy & 100(33.0) & $48(55.2)$ & $2.5[1.5-4.1]$ & $<0.0001$ \\
\hline Neuropathy & $120(38.5)$ & $43(48.3)$ & $1.5[0.9-2.4]$ & 0.112 \\
\hline Macrovascular disease & $30(9.4)$ & $32(36.0)$ & $5.4[3.1-9.6]$ & $<0.0001$ \\
\hline \multicolumn{5}{|l|}{ Additional cardiovascular risk factors } \\
\hline Family history of premature CAD & $27(21.8)$ & $6(24.0)$ & $1.1[0.4-3.1]$ & 0.795 \\
\hline Hypertension & 163(50.9) & $61(69.3)$ & $2.2[1.3-3.6]$ & 0.002 \\
\hline Dyslipidaemia & $171(53.4)$ & $67(76.1)$ & $2.8[1.6-4.8]$ & $<0.0001$ \\
\hline Current smoking & $52(16.2)$ & $19(21.3)$ & $1.4[0.8-2.5]$ & 0.270 \\
\hline Cumulative tobacco consumption (pack-year) & $6.4 \pm 14.1$ & $14.7 \pm 22.8$ & & $<0.0001$ \\
\hline
\end{tabular}

Data: mean \pm standard deviation

$A \cup$ Agatston unit, $C A D$ coronary artery disease, OR odds ratio, $95 \% \mathrm{Cl} 95 \%$ confidence interval

\section{EAT and diabetic microangiopathic complications}

We found that EAT volume was positively associated with albuminuria-without correlation with renal failure-whereas such a correlation was not found previously in the diabetic population [11, 12]. Albuminuria is a known marker of poor cardiovascular prognosis in people with diabetes $[8,10]$. We might hypothesize that the association between EAT and albuminuria only reflects EAT-induced coronary endothelial dysfunction through paracrine effects [30]. On the contrary, EAT volume was lower in case of retinopathy. In the study by Yerramasu et al., the percentage of retinopathy also decreased by increasing EAT tertiles (34, 27 and 23\%, respectively) but statistical significance was not reached $(p=0.18)$ [11]. Whether EAT would play a systemic role on eyes need further specific studies. Finally, as previously reported [11], EAT volume did not differ by presence of neuropathy.

\section{Clinical and therapeutic implications}

Our results suggest that measuring EAT volume might improve assessment of cardiovascular prognosis, but whether the prognostic value of EAT is additional to the one of CAC score is unknown [14, 26, 27]. There are also therapeutic implications of our work. EAT volume can be modified by lifestyle such as diet and/or exercise, bariatric surgery and pharmaceutical interventions [31, 32]. For example, thiazolidinediones, dipeptidyl peptidase- 4 inhibitors, glucagon-like peptide-1 receptor agonists and sodium-glucose cotransporter 2 inhibitors have all been 
Table 4 Parameters explaining a coronary artery calcium score $\geq 100$ Agaston units in multivariable analysis

\begin{tabular}{|c|c|c|c|}
\hline & Odds ratio & $95 \%$ confidence interval & p-value \\
\hline Epicardial adipose tissue (per $10 \mathrm{~cm}^{3}$ ) & 1.13 & $1.04-1.23$ & 0.004 \\
\hline Age (per year) & 1.08 & $1.05-1.12$ & $<0.001$ \\
\hline Body mass index $\left(\right.$ per $\left.\mathrm{kg} / \mathrm{m}^{2}\right)$ & 0.94 & $0.89-1.00$ & 0.051 \\
\hline Male vs Female & & & NS \\
\hline Type 2 vs Type 1 diabetes & & & NS \\
\hline Other diabetes types vs Type 1 diabetes & & & NS \\
\hline Afro-Caribbean vs Caucasian & & & NS \\
\hline Arabic vs Caucasian & & & NS \\
\hline Asia vs Caucasian & & & NS \\
\hline Other vs Caucasian & & & NS \\
\hline Hypertension & & & NS \\
\hline Dyslipidaemia & & & NS \\
\hline Diabetes duration & & & NS \\
\hline Cumulative Tobacco consumption (per pack-year) & 1.03 & $1.01-1.04$ & 0.002 \\
\hline Retinopathy & 1.89 & $0.99-3.58$ & 0.05 \\
\hline Macular edema & & & NS \\
\hline Nephropathy & & & NS \\
\hline Macrovascular disease & 3.94 & $1.92-8.07$ & $<0.001$ \\
\hline
\end{tabular}

reported to reduce EAT volume [33]. On the contrary, CAC cannot regress.

\section{Limitations and strengths of the study}

Our study has several limitations. Its design was observational, which prevented us from being able to draw conclusions about causal relationships between EAT volume and CAC. Neither were we able to make a conclusion about the role of therapy on EAT volume. Furthermore, in order to evaluate the prognostic value of EAT volume, we used a marker of subclinical atherosclerosis (i.e., CAC) instead of measuring the incidence of cardiovascular events. Moreover, we only included patients who had been admitted to our hospital department and who had their CAC score measured. Therefore, our results may not be representative of all patients with diabetes. Finally, we did not have data on waist circumference, which could have influenced the association between EAT volume and CAC. However, we did adjust for several confounders, including BMI.

The main strength of our study is that we measured EAT and not pericardial (or total cardiac) adipose tissue. EAT lies between the myocardium and the visceral layer of the pericardium and is different from pericardial fat which is located externally to the myocardium. There is no fascia separating EAT and myocardium. Therefore both tissues are in direct contact $[3-6,31]$. To date, EAT is the only type of cardiac adipose tissue which has been observed to predict incident cardiovascular events in T2D patients [27]. Furthermore, we applied a robust
methodology-CT acquisition and assessment following standard methods-as well as cardiac software to automatically quantify EAT. Only 1 EAT measure out of the 410 performed (study population) could not be interpreted. CT scans are considered the gold standard for EAT as, unlike echography, they measure EAT volume not thickness $[4,14]$.

\section{Conclusions}

We showed that in individuals with diabetes, EAT volume was higher in males, persons of Caucasian ethnicity and those who met the criteria for the components of metabolic syndrome. More importantly, we demonstrated that EAT was independently associated with subclinical coronary atherosclerosis in our study population. This suggests that EAT quantification might improve early assessment of cardiovascular prognosis. Furthermore, the anatomic proximity of EAT and adjacent myocardial and vascular tissues might provide an opportunity for therapeutic interventions.

\section{Supplementary Information}

The online version contains supplementary material available at https://doi. org/10.1186/s12933-021-01225-6.

Additional file 1: Table S1. Epicardial adipose tissue volume according to cardio-vascular risk factors. Table S2. Epicardial adipose tissue volume according to diabetes-related complications. Table S3. Epicardial adipose tissue volume according to treatment. 


\section{Abbreviations}

AU: Agatston unit; BMI: Body mass index; CAC: Coronary artery calcium; CT: Computed tomography; EAT: Epicardial adipose tissue; PACS: Picture Archiving and Communication Systems; T1D: Type 1 diabetes; T2D: Type 2 diabetes; UACR: Urinary albumin/creatinine ratio.

\section{Acknowledgements}

We thank Sylvain Guillaume and Adeline Digard from GE Healthcare, France, for providing the software to calculate EAT volume. Our thanks also to Jude Sweeney (Milan, Italy) for the English editing and revision of the manuscript.

\section{Authors' contributions}

$\mathrm{EC}$ and $\mathrm{HB}$ conceived and designed this study and had full access to all the study data. EC is responsible for the integrity of the data and the accuracy of the data analyses. IR and PYB collected the data. EC drafted the paper, with help from MTN, IR, ST, PYB and HB. MTN performed the analyses. All authors critically revised the manuscript for important intellectual content. All authors read and approved the final manuscript.

\section{Funding}

Internal funding was provided by Assistance Publique-Hôpitaux de Paris and Paris 13 University.

\section{Availability of data and materials}

Data for the present analysis can be provided from the first author on reasonable request.

\section{Ethics approval and consent to participate}

In Avicenne hospital and in general in the various Public Assistance Hospitals in Paris, all patients are informed at admission that their medical records may be used for research, unless they indicate their opposition. For the present study, no patient indicated opposition. Approval for the use of patient data was provided by the local ethics committee (Approval number: CLEA-2020148). Data were analyzed anonymously. No patient opposed.

\section{Consent for publication}

Not applicable.

\section{Competing interests}

The authors declare that they have no competing interests.

\begin{abstract}
Author details
${ }^{1}$ Department of Endocrinology-Diabetology-Nutrition, AP-HP, Avicenne Hospital, Université Paris 13, Sorbonne Paris Cité, CRNH-IdF, CINFO, Bobigny, France. ${ }^{2}$ Unité de Recherche Epidémiologique Nutritionnelle, UMR U1153 INSERM/U11125 INRA/CNAM/Université Paris 13, Bobigny, France. ${ }^{3}$ Department of Functional Explorations, AP-HP, Jean Verdier Hospital, Université Paris 13, Bondy, France. ${ }^{4}$ Department of Radiology, AP-HP, Avicenne Hospital, Bobigny, France. ${ }^{5}$ Laboratoire Educations et Pratiques de Santé UR 3412, UFR Santé, Médecine, Biologie Humaine, Université Paris Sorbonne Paris Nord, 74, rue Marcel Cachin, 93017 Bobigny Cedex, France.
\end{abstract}

Received: 16 December 2020 Accepted: 22 January 2021 Published online: 05 February 2021

\section{References}

1. Gregg EW, Li Y, Wang J, Burrows NR, Ali MK, Rolka D, et al. Changes in diabetes-related complications in the United States, 1990-2010. N Engl J Med. 2014;370:1514-23.

2. Vergès B. Cardiovascular disease in type 1 diabetes: a review of epidemiological data and underlying mechanisms. Diabetes Metab. 2020;46:442-9.

3. Li Y, Liu B, Li Y, Jing X, Deng S, Yan Y, et al. Epicardial fat tissue in patients with diabetes mellitus: a systematic review and meta-analysis. Cardiovasc Diabetol. 2019;18:3.

4. Villasante Fricke AC, lacobellis G. Epicardial adipose tissue: clinical biomarker of cardio-metabolic risk. Int J Mol Sci. 2019;20:5989.

5. Christensen RH, von Scholten BJ, Lehrskov LL, Rossing P, Jørgensen PG. Epicardial adipose tissue: an emerging biomarker of cardiovascular complications in type 2 diabetes? Ther Adv Endocrinol Metab. 2020;11:2042018820928824.

6. lacobellis G, Barbaro G. Epicardial adipose tissue feeding and overfeeding the heart. Nutrition. 2019;59:1-6.

7. Greenland P, Blaha MJ, Budoff MJ, Erbel R, Watson KE. Coronary calcium score and cardiovascular risk. J Am Coll Cardiol. 2018;72:434-47.

8. Cosentino F, Grant PJ, Aboyans V, Bailey CJ, Ceriello A, Delgado V, et al. 2019 ESC guidelines on diabetes, pre-diabetes, and cardiovascular diseases developed in collaboration with the EASD. Eur Heart J. 2020;41:255-323

9. Fox CS, Golden SH, Anderson C, Bray GA, Burke LE, de Boer IH, et al. Update on prevention of cardiovascular disease in adults with type 2 diabetes mellitus in light of recent evidence: a scientific statement from the American Heart Association and the American Diabetes Association. Diabetes Care. 2015;38:1777-803.

10. Valensi P, Belle EV, Cosson E, Emmerich J, Prevost G, Ferrières J, et al. Risk stratification and screening for coronary artery disease in asymptomatic patients with diabetes mellitus. Diabetes Metab. 2020. https://doi. org/10.1016/j.diabet.2020.08.002.

11. Yerramasu A, Dey D, Venuraju S, Anand DV, Atwal S, Corder R, et al. Increased volume of epicardial fat is an independent risk factor for accelerated progression of sub-clinical coronary atherosclerosis. Atherosclerosis. 2012;220:223-30.

12. Zobel EH, Christensen RH, Winther SA, Hasbak P, Hansen CS, von Scholten $\mathrm{BJ}$, et al. Relation of cardiac adipose tissue to coronary calcification and myocardial microvascular function in type 1 and type 2 diabetes. Cardiovasc Diabetol. 2020;19:16.

13. Reinhardt M, Cushman TR, Thearle MS, Krakoff J. Epicardial adipose tissue is a predictor of decreased kidney function and coronary artery calcification in youth- and early adult onset type 2 diabetes mellitus. J Endocrinol Invest. 2019;42:979-86.

14. Christensen RH, von Scholten BJ, Hansen CS, Heywood SE, Rosenmeier $J B$, Andersen UB, et al. Epicardial, pericardial and total cardiac fat and cardiovascular disease in type 2 diabetic patients with elevated urinary albumin excretion rate. Eur J Prev Cardiol. 2017;24:1517-24.

15. Hecht HS, Cronin P, Blaha MJ, Budoff MJ, Kazerooni EA, Narula J, et al. 2016 SCCT/STR guidelines for coronary artery calcium scoring of noncontrast noncardiac chest CT scans: a report of the Society of Cardiovascular Computed Tomography and Society of Thoracic Radiology. J Thorac Imaging. 2017;32:W54-66

16. Wang C-P, Hsu H-L, Hung W-C, Yu T-H, Chen Y-H, Chiu C-A, et al. Increased epicardial adipose tissue (EAT) volume in type 2 diabetes mellitus and association with metabolic syndrome and severity of coronary atherosclerosis. Clin Endocrinol. 2009;70:876-82.

17. Pierdomenico SD, Pierdomenico AM, Cuccurullo F, lacobellis G. Metaanalysis of the relation of echocardiographic epicardial adipose tissue thickness and the metabolic syndrome. Am J Cardiol. 2013;111:73-8.

18. Colom C, Viladés D, Pérez-Cuellar M, Leta R, Rivas-Urbina A, Carreras G, et al. Associations between epicardial adipose tissue, subclinical atherosclerosis and high-density lipoprotein composition in type 1 diabetes. Cardiovasc Diabetol. 2018;17:156.

19. Svanteson M, Holte KB, Haig Y, Kløw NE, Berg TJ. Coronary plaque characteristics and epicardial fat tissue in long term survivors of type 1 diabetes identified by coronary computed tomography angiography. Cardiovasc Diabetol. 2019;18:58.

20. Cena H, Fonte ML, Turconi G. Relationship between smoking and metabolic syndrome. Nutr Rev. 2011;69:745-53.

21. Salami SS, Tucciarone M, Bess R, Kolluru A, Szpunar S, Rosman H, et al. Race and epicardial fat: the impact of anthropometric measurements, percent body fat and sex. Ethn Dis. 2013;23:281-5.

22. Willens HJ, Gómez-Marín O, Chirinos JA, Goldberg R, Lowery MH, lacobellis G. Comparison of epicardial and pericardial fat thickness assessed by echocardiography in African American and non-Hispanic White men: a pilot study. Ethn Dis. 2008;18:311-6.

23. Apfaltrer P, Schindler A, Schoepf UJ, Nance JW, Tricarico F, Ebersberger $U$, et al. Comparison of epicardial fat volume by computed tomography in black versus white patients with acute chest pain. Am J Cardiol. 2014;113:422-8.

24. El Khoudary SR, Shin C, Masaki K, Miura K, Budoff M, Edmundowicz D, et al. Ectopic cardiovascular fat in middle-aged men: effects of race/ 
ethnicity, overall and central adiposity. The ERA JUMP study. Int J Obes. 2015;39:488-94.

25. Adams DB, Narayan O, Munnur RK, Cameron JD, Wong DTL, Talman AH, et al. Ethnic differences in coronary plaque and epicardial fat volume quantified using computed tomography. Int J Cardiovasc Imaging. 2017;33:241-9.

26. Mahabadi AA, Berg MH, Lehmann N, Kälsch H, Bauer M, Kara K, et al. Association of epicardial fat with cardiovascular risk factors and incident myocardial infarction in the general population: the Heinz Nixdorf Recall Study. J Am Coll Cardiol. 2013;61:1388-95.

27. Christensen RH, von Scholten BJ, Hansen CS, Jensen MT, Vilsbø\|l T, Rossing P, et al. Epicardial adipose tissue predicts incident cardiovascular disease and mortality in patients with type 2 diabetes. Cardiovasc Diabetol. 2019;18:114.

28. Nerlekar N, Brown AJ, Muthalaly RG, Talman A, Hettige T, Cameron JD, et al. Association of epicardial adipose tissue and high-risk plaque characteristics: a systematic review and meta-analysis. J Am Heart Assoc. 2017;6:e006379.

29. Nakahara T, Dweck MR, Narula N, Pisapia D, Narula J, Strauss HW. Coronary artery calcification: from mechanism to molecular imaging. JACC Cardiovasc Imaging. 2017;10:582-93.

30. Cosson E, Pham I, Valensi P, Pariès J, Attali J-R, Nitenberg A. Impaired coronary endothelium-dependent vasodilation is associated with microalbuminuria in patients with type 2 diabetes and angiographically normal coronary arteries. Diabetes Care. 2006;29:107-12.

31. Rafeh R, Viveiros A, Oudit GY, El-Yazbi AF. Targeting perivascular and epicardial adipose tissue inflammation: therapeutic opportunities for cardiovascular disease. Clin Sci. 2020;134:827-51.

32. Launbo N, Zobel EH, von Scholten BJ, Faerch K, Jørgensen PG, Christensen RH. Targeting epicardial adipose tissue with exercise, diet, bariatric surgery or pharmaceutical interventions: a systematic review and metaanalysis. Obes Rev. 2020. https://doi.org/10.1111/obr.13136.

33. Xourgia E, Papazafiropoulou A, Melidonis A. Effects of antidiabetic drugs on epicardial fat. World J Diabetes. 2018;9:141-8.

\section{Publisher's Note}

Springer Nature remains neutral with regard to jurisdictional claims in published maps and institutional affiliations.
Ready to submit your research? Choose BMC and benefit from:

- fast, convenient online submission

- thorough peer review by experienced researchers in your field

- rapid publication on acceptance

- support for research data, including large and complex data types

- gold Open Access which fosters wider collaboration and increased citations

- maximum visibility for your research: over 100M website views per year

At BMC, research is always in progress.

Learn more biomedcentral.com/submissions 